Rev. Elet. Gestão e Serviços

V.7, n.2, Jul./Dez. 2016

\title{
Qualidade Total em Serviços no Contexto Brasileiro
}

Tiago Eloy Zaidan1

1 Mestre em Comunicação Social pela Universidade Federal de Pernambuco. Unidade Acadêmica de Gestão e Negócios do Instituto Federal de Educação, Ciência e Tecnologia da Paraíba (UAG - IFPB). E-mail: eloyzaidan@gmail.com

Resenha recebida em: 25 de outubro de 2015. Artigo aceito em 02 de março de 2017. 
Imagine a seguinte situação, a qual não é muito difícil, em se tratando da prestação de serviços no Brasil: Um sujeito liga para uma faculdade para contatar o Departamento de Administração do Setor de Pós-Graduação. Contudo, não obtém sucesso, por um simples motivo. A atendente não espera o interlocutor concluir a frase ao telefone, e o transfere sistematicamente para o setor errado. O máximo que o sujeito consegue falar é "gostaria de falar com o departamento de administração...". E a conversa é interrompida com a transferência indevida. A solução encontrada pelo interlocutor é, na terceira tentativa, inverter a ordem da frase: "Pós-graduação! Departamento de Administração. Queria falar, por favor. Bom dia” (LAS CASAS, 2008, p.3).

A experiência relatada foi vivenciada justamente - e ironicamente - pelo autor do livro Qualidade Total em Serviços: Conceitos, Exercícios, Casos Práticos, Andre Luzzi Las Casas, o qual é mestre em Administração de Empresas pela Pontifícia Universidade Católica de São Paulo (onde é professor titular) e doutor em Administração Mercadológica pela Fundação Getúlio Vargas-SP. Las Casas é, também, consultor de empresas e autor de outros livros nas áreas de marketing e vendas.

Em Qualidade Total em Serviços, o objetivo central é a aplicação da qualidade aos serviços, com foco nas estratégias ligadas aos aspectos internos do negócio embora a qualidade envolva também aspectos externos. Para tratar do último prisma, o autor escreveu Marketing de serviços, também lançado pela editora Atlas.

A abordagem dos aspectos internos é pertinente, na medida em que sem o apoio efetivo dos administradores, os quais também precisam dar bons exemplos, e a participação ativa dos funcionários, uma instituição não consegue oferecer um serviço de qualidade. Aliás, "a palavra funcionárioé a chave na prestação de serviços. São eles que falam com os consumidores" (LAS CASAS, 2008, p.22). Por isso, um dos passos iniciais para se alcançar a qualidade é a disponibilização das ferramentas necessárias à equipe e a valorização do corpo funcional (LAS CASAS, 2008, p. 190).

A qualidade de um serviço está diretamente relacionada a uma cultura de priorização dos clientes, o que passa por um bom atendimento, evidentemente diferente daquele ilustrado na história citada. Pode parecer óbvio, mas, para muitas empresas, aparentemente, não é.

Muitas organizações priorizam os procedimentos em detrimento dos clientes. Esse é o caso de uma lanchonete, que, diante de uma solicitação do consumidor, nega-se 
a trocar um ingrediente pelo outro no prato executivo disponível no cardápio. Mesmo com o cliente dispondo-se a pagar pelo serviço adicional. "É contra o procedimento", diria o garçom. Pior. Antes de sentenciar a recusa, faria o consumidor esperar, pois, em um interlúdio, seria preciso consultar o superior a respeito doapelo do cliente. Diante disso, Las Casas diria que está tudo errado. E não apenas pelo fato do procedimento ter sido colocado em um patamar superior ao cliente.

Os resultados devem ser, de fato, mais importantes que os procedimentos (LAS CASAS, 2008, p.28, 34). E os resultados que interessam são espelhados na satisfação dos clientes. O outro erro é a obtusa burocratização no atendimento. Se o funcionário possuísse relativa autonomia, poderia ele próprio ter resolvido a demanda, agilizando o processo (LAS CASAS, 2008, p.33).

A área de serviços é notadamente marcada pela existência do componente da intangibilidade - embora um olhar acurado revele que, em maior ou menor grau, quase sempre pode ser divisado um componente tangível no bojo da prestação de um serviço ao cliente. No caso do restaurante, mencionado no exemplo, o cliente se depara com a refeição (tangível) e o atendimento (intangível) (LAS CASAS, 2008, p.12). Apesar da existência desse percentual palpável, na área de serviços, comercializa-se, sobretudo, “atos, ações, desempenho" (LAS CASAS, 2008, p.5).

O nível de satisfação ou insatisfação de um cliente com relação a um serviço é dotado de alguma complexidade, pois depende, em certo sentido, das expectativas do consumidor - as quais trazem consigo, evidentemente, uma carga de abstração. "Se os serviços igualarem ou superarem as expectativas haverá satisfação. Se forem inferiores, haverá insatisfação. Quando o resultado supera a expectativa, diz-se que a empresa atingiu a excelência em serviços" (LAS CASAS, 2008, p.6).

Abstrações à parte, algumas medidas concretas podem contribuir com a construção de uma imagem positiva na mente do consumidor. Uma delas é a criação de uma cultura de cooperação entre os funcionários. Em um contexto de funções rigidamente delimitadas, um funcionário não colabora com outro, mesmo que esteja livre e o outro precisar de sua ajuda. A lógica é: a atividade do outro ultrapassa as minhas atribuições. E uma das coisas que mais incomodam os clientes é esperar, numa fila custosa, o atendimento por um funcionário bastante demandado, enquanto outro apenas folheia uma revista ou navega no smartphone. O ideal é que os colaboradores 
façam jus a tal denominação e sejam “(...) treinados para trabalhar em outros setores e auxiliar os colegas" (LAS CASAS, 2008, p. 31).

Outros tantos caminhos em busca da qualidade passam pelo treinamento do público interno. Las Casas (2008, p. 120) explica que, basicamente, há dois tipos de treinamento:

a. Aquele voltado para os colaboradores novatos, o qual se dedica, principalmente, a apresentar a organização ao novo funcionário e a introduzi-lo nos procedimentos, visando a uma relativa padronização na prestação do serviço, necessária a construção de uma imagem coerente para a instituição (LAS CASAS, 2008, p.14); e

b. Os treinamentos de reciclagem, voltados para os colaboradores veteranos, oferecidos de modo específico a partir da “(...) identificação dos pontos fracos de alguns funcionários (...)” (LAS CASAS, 2008, p. 121).

Recomenda-se que os treinamentos sejam calcados em necessidades concretas previamente identificadas - e tenham objetivos redundantes de tais necessidades (LAS CASAS, 2008, p. 123, 124). Uma forma producente de se chegar às necessidades são as pesquisas de atendimento, as quais possibilitam auscultar os clientes a respeito do atendimento recebido. Os resultados de tais pesquisas fornecem indicadores do que precisa ser melhorado.

Existem várias formas de se coletar dados, da entrevista à disponibilização de formulários simples, em pontos estratégicos, convidando o cliente a opinar. $\mathrm{Na}$ Walt Disney Word, tais formulários fazem alusão às orelhas icônicas de Mickey Mouse, com a frase convidativa: "somos todos ouvidos", segundo faz saber Mercedes Reincke, citada por Las Casas (2008, p.43).

O questionário básico de avaliação de um serviço pelo cliente, sugerido no livro Qualidade Total em Serviços, traz, no mínimo, os seguintes tópicos, com as respectivas lacunas para preenchimento:

a. Nota de avaliação (de um a cinco);

b. Pontos fortes;

c. Pontos fracos; e

d. Sugestões (LAS CASAS, 2008, p. 63).

Muitas empresas já disponibilizam tais pesquisas, por meio de terminais eletrônicos, no próprio local de atendimento ou de prestação do serviço. Não é 
necessário, no entanto, apelar para a tecnologia. "Um instrumento sem nenhuma sofisticação já permite iniciação de qualquer um aos princípios de qualidade" (LAS CASAS, 2008, p. 63).

Justificativas para se encetar esforços em busca da qualidade não faltam. Las Casas cita uma pesquisa que revela “(...) que o crescimento médio anual das empresas voltadas ao cliente e que aplicam qualidade total é na ordem de $10 \%$, enquanto outras empresas sem esta preocupação não apresentaram crescimento" (LAS CASAS, 2008, p.18). Além disso, há evidências de que as providências para repor um cliente sejam mais caras que aquelas destinadas a manter um cliente na empresa (LAS CASAS, 2008, p.19). Como se não bastasse, há, ainda,o indefectível risco que uma organização corre quando se cultiva clientes insatisfeitos. Principalmente, na era das redes sociais. Um consumidor frustrado é um potencial propagandista das falhas da empresa e de seu atendimento. Por sua vez, um cliente satisfeito e fiel pode assumir uma postura cooperativa, indicando a instituição para outras pessoas (LAS CASAS, 2008, p.20-21).

Embora países desenvolvidos como Estados Unidos e Japão estejam na vanguarda da qualidade, o autor é taxativo ao defender a necessidade da adaptação das técnicas da qualidade total aplicadas no exterior ao Brasil. A cópia ipsis litteris das experiências estrangeiras em um contexto como o brasileiro não é recomendada, até pelas diferenças culturais e econômicas (LAS CASAS, 2008, p.1).

No Brasil, a bem da verdade, antes de se falar em qualidade total, as organizações ainda precisam correr atrás da boa prestação dos serviços básicos. Explicase: A qualidade pode ser um atributo do produto essencial ou do produto ampliado. $\mathrm{O}$ primeiro diz respeito àquilo “(...) que a empresa se propõe a fazer como base de sua comercialização” (LAS CASAS, 2008, p. 186). Já o segundo, “(...) é tudo aquilo que se agrega no produto essencial, ou produto núcleo, para aumentar os benefícios proporcionados aos clientes" (LAS CASAS, 2008, p. 186). A qualidade total ocorre quando os dois aspectos, o essencial e o ampliado, são contemplados. No setor de serviços brasileiro, a despeito do mito da inefabilidade do setor privado (principalmente quando relativizado com o setor público), já seria um avanço se a prestação dos serviços básicos se desse com qualidade (LAS CASAS, 2008, p. 186).

A conclusão a que chega Las Casas, após anos de pesquisas e consultorias é aquela que os consumidores brasileiros, após anos de experiências empíricas, também poderiam chegar. A de que: 
(...) o que necessitamos no Brasil prioritariamente é atender as necessidades e desejos dos clientes com bons produtos e bons serviços. Só devemos fazer ampliações de serviços quando o produto ou serviço básico estiver bem delineado. Ai então estaremos prontos para atender às exigências da qualidade total (LAS CASAS, 2008, p. 187).

\section{REFERÊNCIA}

LAS CASAS, Alexandre Luzzi. Qualidade Total em Serviços: Conceitos, Exercícios, Casos Práticos,6.ed., São Paulo: Atlas, 2008, 223p. 